\title{
Trends in Surgical Treatment of Pilonidal Sinus Diseases: Primary Closure or Flap: Reply
}

\author{
Ahmet Okuş • Banş Sevinç • Ömer Karahan
}

Published online: 1 May 2012

(C) Société Internationale de Chirurgie 2012

In our recent article [1], the results of tension-free primary closure and of the Limberg flap were similar. These results have caused immediate comment [2, 3]. Azizi et al. [4] reported no recurrence at 1 -year follow-up after performing the Limberg flap procedure. In addition, there are studies that reported a $1 \%$ recurrence rate after flap reconstruction for pilonidal sinus [5] in our country. Therefore, flap reconstruction is a highly chosen procedure. However, as Azizi et al. [4] reported, there is no consensus among surgeons about the ideal treatment method. There are successful results for primary closure but the choices of surgeons show variability in the treatment method.

In our study we tried to find whether there is a commonality between the different procedures. Our results showed that being tension-free is the key to reduce recurrences. We are glad that our study triggered the search for the ideal procedure. Moreover, we agree with the other researchers that only time will tell the truth $[1,2]$.

Additional studies will clarify the situation. For this purpose we have begun a randomized prospective study that compares the results of tension-free primary closure, tension-free primary oblique closure, and Limberg flap reconstruction. The study began 4 months ago and when it is finished we will publish the results.

\section{References}

1. Okuş A, Sevinç B, Karahan O, Eryilmaz MA (2012) Comparison of Limberg flap and tension-free primary closure during pilonidal sinus surgery. World J Surg 36(2):431-435. doi:10.1007/s00268011-1333-y

2. Cheetham M (2012) Lateral incision surgery for pilonidal sinus: death of a dogma. World J Surg 36(2):436. doi:10.1007/s00268011-1388-9

3. Azizi R, Alemrajabi M (2012) Trends in surgical treatment of pilonidal sinus diseases; primary closure or flap? World J Surg. doi:10.1007/s00268-012-1551-y

4. Azizi R, Alemrajabi M, Pezhoman A (2009) Medium-term follow up of the surgical complication of Limberg flap technique in pilonidal sinus operation. Iran J Surg 16(3):45-50

5. Akın M, Leventoglu S, Mentes BB et al (2010) Comparison of the classic Limberg flap and modified Limberg flap in the treatment of pilonidal sinus disease: a retrospective analysis of 416 patients. Surg Today 40:757-762

\footnotetext{
A. Okuş · B. Sevinç $(\bowtie) \cdot$ Ö. Karahan

Department of General Surgery, Konya Education and Research

Hospital, Konya, Turkey

e-mail: drbarissevinc@gmail.com
} 